\title{
SPORT U METAFORI I METAFORA U SPORTU
}

\author{
Dalibor Kesić ${ }^{1}$ i Emir Muhić ${ }^{1}$
}

${ }^{1}$ Filološki fakultet, Univerzitet Banja Luka, Bosna i Hercegovina

\section{SAŽETAK}

Tema ovog rada su metafore i idiomi u engleskom jeziku koji kao motivacionu osnovu imaju sport, te težnja da se povuku određene paralele sa njihovim korespondentnim semantičkim ekvivalentima u srpskom jeziku. Spoznati porijeklo bilo kojeg idioma nije jednostavan zadatak. Još je teže razvrstati ih u grupe na osnovu njihove metaforičke motivacije. Jedna od grupa koju vrijedi istražiti odnosi se na za koje se čini da su motivisane sportom. Moguće je da njihovo značajno prisustvo među metaforičkim konstrukcijama zasnovano na njihovoj pogodnosti jer predstavljaju igrokaz između različitih značenja od kojih neka zaista prava igra među ljudima. Ono što ih razlikuje od ostalih vrsta izražavanja je činjenica dao uključuju terminologiju iz sporta a odnose se na nešto potpuno drugo, ponekad uključujući običan narod a ponekad visoke zvaničnike. No, ono što im je svima zajedničko je transfer značenja, iz jednog semantičkog polja u sasvim drugu arenu, u ovom slučaju u sportsku arenu. Ovim se implicira da frazeologija uključuje izreke, poslovice, idiolekt i svaki drugi oblik kolociranog iskaza kojim se denotira određeni objekat, savjet, ideja ili bilo šta drugo čije značenje u određenoj mjeri odudara od doslovnog značenja riječi koje su u njima sadržane. U dijelu o metodologiji, rad detaljnije razmatra više od 20 različitih metaforičkih izraza koji uključuju sportsku terminologiju, dok uvod, rezultati, diskusija i zaključak preispituju teoretske osnove koje leže u osnovi bilo kojeg obrta u značenju kada se grupa od nekoliko riječi udruži na takav način da im se promijeni zbir individualnog značenja.

Klučne riječi: metafora, sport, jezik, značenje, motivacija, engleski, srpski.

\section{UVOD}

U svakom kulturološkom kontekstu i u svakom jeziku postoje tipični modusi izražavanja koji udružuju riječi u svrhu označavanja nečega što nije ograničeno na zbir njihovog individualnog značenja u smislu riječi koje ih čine; dodatno značenje, uglavnom metaforičko postaje sastavni dio tog udruživanja. Poseban vid metaforičkog izražavanja može se vidjeti u frazeologizmima i idiomima. Idiomi i frazeologizmi se ne stvaraju slučajno; oni su raskršća kolektivne misli i mudrosti do koje se dolazi na sažet način uz prenošenje značenja. Spoznati im porijeklo nije lak zadatak. No, ukoliko se opredijelimo da se prihvatimo takvog poduhvata ubrzo ćemo shvatiti da je njihova geneza motivisana različitim aspektima ljudske egzistencije, pri čemu sport igra bitnu ulogu. I kako raste znanje o frazeologiji, i kako se javljaju nove istorijske informacije, čini se da se javlja i sve više pitanja o tome zašto se određene riječi i koncepti uključuju u idiome i kada su se kao takvi prvi put počeli koristiti.

Čini se da su odgovori na gorenavedena pitanja još više bitni u situacijama u kojima određeni idiomi i metafore trebaju biti prevedeni na neki drugi jezik. Leksički sastav idioma u jednom jeziku ne mora pod obavezno da odgovora leksičkom sastavu idioma u drugom jeziku. Metafore u kojima je sport generator i pokretač leksičkog sastava mogu biti iskazane putem potpuno drugog aspekta ljudske ili prirodne interakcije u drugom jeziku. Ovaj rad razmatra metafore i idiome u engleskom jeziku koji su motivisani sportom, te pokušava da povuče određene paralele sa korespondentnim semantičkim ekvivalentima u srpskom jeziku. Ovo može biti od većeg značaja u prevodilačkoj praksi jer, baš kao što Anuradha Dingwaney (1995) reče - prevesti metaforu iz jednog jezika u drugi uključuje određenu količinu nasilja u značenju, pogotovo kada se kultura koja se prevodi čini odveć stranom. 


\section{METODE}

\section{Definisanje uzorka}

Idiomi su već više decenija dio lingvistike koji nikada nije decidno definisan. Definicije frazeologije su sve samo ne doslijedne. Za to postoji više razloga. Određeni autori na frazeologizme gledaju kao na nešto što ima ustaljenu formu, bez varijacija u leksičkom sastavu, bez obzira na upotrebu, žanr, ekspresivnost, poetsku notu ili učestalost u upotrebi dok god u njima postoji nevarijabilan leksički sastav koji je kao takav poznat govornicima datog jezika. Ovo bi podrazumijevalo da frazeologija obuhvata izreke, poslovice, idiolekt i svaki drugi oblik kolociranog iskaza kojim se denotira određeni objekat, savjet, ideja ili bilo šta drugo sa značenjem koje, u određenoj mjeri, odudara od doslovnog značenja riječi koje su korištene u njima. Drugi su mnogi strožiji u razumijevanju frazeologije i smatraju da samo one jezičke konstrukcije koje imaju značenje koje je jasno različito od zbira značenja odvojenih riječi mogu biti nazvani metaforičkim frazeologizmima.

Popularne izreke se mogu generalno podijeliti u pet kateogirja:

Istorijske - popularne izreke koje se pripisuju čuvenim ljudima iz prošlosti (kao na primjer Poslije nas potop od Marije Antoanete), naučne - popularne izreke koje se pripisuju velikim naučnicima ili filozofima (kao što je recimo Arhimedova Eureka.); književne - popularne izreke koje se pripisuju čuvenim piscima (kao što je recimo Šekspirovo - Citav svijet je pozornica); patriotske - popularne izreke koje su skovali britanske ili američke vojskovođe (kao što je recimo Tomas Džeferson i njegovo Svi ljudi su stvoreni jednaki); ili sportski - popularne izreke koje se pripisuju bitnim ljudima iz svijeta sporta ili novinarima (kao što su Joe Louis, Knute Rockne, Vince Lombardi): You can run, but you can't bide (Možešs da bje žis, ali ne možes da se sakriješ); Win this one for the Gipper (Pobijedite ovaj put za Gippera); Winning isn't everytbing, it's the only thing (Pobjeda nije sve, ali jeste jedina stvar) itd (Titelman, 2000).

S obzirom da se ovaj rad fokusirana na metafore u sportu i sport u metaforama, uzorak koji razmatra jesu 24 izreke koje uključuju sport kao motivacionu osnovu, sa određenim objašnjenjima u pogledu njihovog značenja, kako su ušle u opticaj i kada su prvi put upotrebljene:

The ball is in your court. (Lopta je u vašem terenu/dvoristu) - sa znă̌enjem - Sada je red na vas da napravite naredni poter. Potiče iz Sjedinjenih Američkih Država sa polovine dvadesetog vijeka i odnosi se na igru tenisa. Umjesto riječi court/teren mogu se koristiti i druge riječi.
Don't change the rules in the middle of the game. (Ne mijenjaj pravila u sredini utakmice) - sa značenjem - Kada se ljudi upuste u nešto pod pretpostavku da su obavezani na određena pravila, imaju pravo da se ljute ako se ta pravila promijene jednostrano. Često se skraćuje $\mathrm{u}$ don't change the rules/ ne mijenjaj pravila.

Don't hit a man when he's down. (Ne udaraj corjeka dok je na podu) - sa značenjem - Ne napadaj na onoga koji je već povrijeđen. Fraza izvorno potiče iz boksa. Prema pravilima boksa, drugog boksera se ne smije udariti dok je na podu; udariti ga možeš jedino kada ustane nakon pada. Ova se izreka može pratiti sve do Odgovora Gardineru od strane Tomasa Krenmera u šenaestom vijeku. Ovu izreku možemo čuti u različitim oblicima: Never hit a man when he's down; Never kick a guy except when he is down; You can't kick a man when he's down, etc. Takođe se koristi i metaforička fraza to bit a man when he's down/ udariti corjeka dok je na podu.

Don't play with fire (Ne igraj se vatrom) - sa značenjem - Ne prihvataj se nepotrebnih rizika. Ovu frazu nalazimo zabilježenu prvi put u Americi kod Judžina O’Nila (1928), u Strange Interlude, a takođe je možemo čuti u različitim oblicima: If you play with fire, you're apt to get burned; itd.

Don't put the cart before the horse (Ne stavljaj zapregu prije konja; Ne trči pred rudu) - sa značenjem - Ne remeti ispravan redoslijed aktivnosti. Ova se izreka može naći u raznim oblicima: Don't get the cart before the horse; itd. To put the cart in front of the horse (Staviti rapregu prije konja) znači raditi stvari pogrešnim redoslijedom, i često se koristi kao stilska figura sa prenesenim značenjem. Slične fraze korištene su još u doba grčkih olimpijskim igara.

Don't swap horses in midstream (Ne mijenjaj konje na sredini vodotoka; Ne mijenjaj konje na uzbrdici) - sa značenjem - ne mijenjaj vođe u toku važnih poduhvata. Vjerovatno potiče iz Sjedinjenih Američkih Država. Koristio ju je čak i Abraham Linkoln tokom svoje predsjedničke kampanje 1864. godine. Izreka se često skraćuje i u to swap (change) horses in midstream. (Mijenjati konje na sredini vodotoka).

The game is not worth the candle (Igra nije vrijedna svijeća; Skuplja pita od tepsije) - sa značenjem da uloženi trud ne donosi adekvante rezultate. Potiče još iz doba prije elektrifikacije kada su se za osvjetljivanje koristile svijeće, pa otuda i aluzija na utrošak svijeća tokom igre. Fraza je inače francuskog porijekla. Zabilježeno je da ju je Michel de Montaigne (1533-1592) izrekao Le jeu ne vaut pas la chandelle. 1678. godine je uključena u zbirku poslovica Johna Raya. Iako se često koristi u negativnoj konotaciji, ima i svoju afirmativnu verziju, The game is worth the candle, (Igra vrijedi svijecia).

It takes two to tango (Za tango je potrebno dvoje) - sa značenjem da je za ostvarivanje određenih aktivnosti 
neophodno učestvovanje obije strane. Potiče iz Sjedinjenih Američkih Država iz 1920ih godina. Popularizovao ju je Pearl Bailey u pjesmi "Takes Two to Tango" iz 1952. godine (Hoffman i Maning, 1952).

It's a different (new) ball game (ballpark) (To je drugačija Inoval igra) - sa značenjem da su se stvari radikalno promijenile; nova situacija uopšte ne liči na prethodnu. Fraza je prvobitno imala doslovno značenje da je u pitanju igra koja se razlikuje od bejzbola, kao što je košarka, nogomet i slično. Uobičajena je od 1930ih godina, i danas se više koristi u prenesenom značenju. Često se prije riječi different ili new koristi riječ whole.

It's not over till it's over (Nije gotovo dok se ne zavrsí) - sa značenjem da nikada ne treba gubiti nadu dok god se stvari u potpunosti ne završe: u životu, kao i u bejzbolu, čuda se ponekad dese. Pripisuje se Yogi Berri, da ju je izrekao misleći na New York Metse. It ain't over till it's over and It's never over till it's over su varijacije istog frazeologizma. Za Džordža Buša važi da je često znao reći "Politics is like baseball. It isn't over till the last batter swings" (Politika je poput bejzbola. Ništa nije gotovo do posljednjeg udarca policom).

It's survival of the fittest (Opstaju samo najspremniji) - sa značenjem da samo najsnažniji mogu da opstanu. Izreka datira iz druge polovine devetnaestog vijeka uz Darvinovu teoriju o prirodnoj selekciji kao "preživljavanju naprilagođenijih". Kasnije je ovaj princip evolucijskog napretka primijenjen na bilo koji oblik borbe za opstanak ili napredak.

It's the only game in town (To je jedina igra u gradu) - sa značenjem da je u pitanju jedina opcija koja stoji na raspolaganju. Datira iz 1900. godine ili možda i ranije. Potpuna verzija glasi: I know it's crooked, but it's the only game in town. U Hollywood Husbands, Jackie Collins (1986) je modifikovala staru izreku dodavši joj nešto veoma blisko i dopadljivo: "It's the only ballgame in the park." Često se skraćuje u the only game in town.

Monday morning quarterbacking (Kvoterbeking ponedjeljkom ujutro; Poslije bitke svi su generali) - sa značenjem naknadnog pametovanja. Kritikovanje nakon su se stvari već desile. Američki fudbal se tradicionalno igra nedjeljom, tako da je ponedjeljak obično doba kada se analiziraju greške iz mečeve koje su napravili kvoterbekovi, i postuliranje onoga što su inače trebali da urade. Monday morning quarterback je takođe uobičajen oblik.

Slow and steady wins the race (Sporo i polako donosi pobjedu u trci; Š to je brzo to je kuso; Prijeko precé, a okolo bliže) - sa značenjem da istrajnost dovodi do uspjeha. Leksikografi na ovo uglavnom gledaju iz ugla Ezopove basne o zecu i kornjači. Zec, ubijeđen da će pobijediti sporu kornjaču, zaspi nakon brzog trčanja dok kornjača sporo ali sigurno nastavlja do cilja prva.
Takođe se može naći u obliku: Slow and easy wins the race.

Step up to the plate (Zakorači na ploču) sa značenjem hrabrog preuzimanja odgovornosti. Ova američka fraza je skorašnjeg porijekla i dolazi iz bejzbola. Aluzija je na 'plate' gdje stoji udarač okrenut prema bacaču.

That's the name of the game (To je naziv igre) - sa značenjem da je pitanju najkrucijalniji dio nečega. Ova izreka potiče iz Amerike, iz ranih šezdesetih godina prošlog vijeka, a postala je uobičajena od 1965. Godine. Pupularizovana je kroz film: Fame is the Name of the Game (MacDougall, 1966) and i TV seriju, The Name of the Game (1968-1971).

There's no joy in Mudville (Nema radosti u Madvilu) - sa značenjem - izgubljena je sva nada u pobjedu a poraz nije lako podnijeti. Frazu je skovao američki tekstopisac Ernest Lawrence Thayer (1863-1940), čija je pjesma, "Casey at the Bat," objavljena 3. Juna, 1888. godine u San Francisco Examineru, postala hit preko noći. Fanovi Madvila su očekivali da pobijedi njihov bejzbol tim, ali uslijedilo je veliko razočarenje kada je njihov omiljeni Casey izgubio. Fraza se često koristi u varijantama sa drugim toponima.

Trust everyone, but cut the cards (Vjeruj svima, ali ipak presijeci špil) - sa značenjem - U redu je vjerovati svima, ali ipak treba preduzeti mjere predostrožnosti kako bismo se zaštitili u svakom slučaju. Fraza potiče iz igre kartama gdje igrači presijecaju špil da bi izbjegli varanje. Koristio ju je Finley Peter Dunne (18671936) u Mr. Dooley's Opinions (1901). Fraza je američka varijanta ruske: Аоверяй, но проверяй ("Vjeruj ali provjeri”) a popularizovao ju je predsjednik Regan.

Always trust your fellow man. And always cut the cards. - Robert Fulghum (1986), All I Really Need to Know I Learned in Kindergarten.

Turnabout is fair play (Preokretje ferplej) - sa značenjem da nema ničega spornog u preokretima. Izreka datira još iz 1755. godine u the Life of Captain Dudley Bradstreet, a književnu upotrebu stekla je uz pomoć škotskog romanopisca Roberta Luisa Stevensona (1868-1894) i američkog pisca Lloyda Osborna (1868-1947) u romanu The Wrecker (1892).

You had your chance then; seems to me it's mine now. Turn about's fair play. - Robert Louis Stevenson \& Lloyd Osborne, The Wrecker (Titelman 2000).

Who's counting? (Ko broji) - sa značenjem - Nikoga nije briga, tako da - samo naprijed, radite kako vam milo. Riječ But često prethodi izreci.

"The target will be reached in six minutes, thirtyfour seconds unless we encounter unexpected head winds over the mountains which will extend our time to six minutes, fourty-eight seconds or perhaps fifty- 
five seconds, but then who's counting?" - Robert Ludlum (1988), The Icarus Agenda.

Win this one for the Gipper (Pobijedite ovaj put za Gippera) - sa značenjem - Ako je potreban razlog za pobjedu, uradite to za nekoga ko vas inspiriše. Izreka potiče iz Amerike iz 20ih godina prošlog vijeka a pripisuje se Knutu Rockneu, tadašnjem treneru tima Notre Dame. Jedan od njegovih najboljih igrača, George Gipp (Gipper), umro je u dvadeset i četvrtoj godini. Prije nego što je umro, rekao je Knutu Rockneu: "Rock, jednoga dana kada stvari ne budu izgledale dobro za Notre Dame, pitaj momke da izađu i pobijede za mene." Trener mu je ispunio posljednju želju i Notre Dame je pobijedio Army do tada neviđenim rezultatom od 12-6. 1940. godine, snimljen je film Knute Rockne - All-American (Robert Buckner, 1940), zasnovan na životu Georgea Gippa, a Gippa je glumio Ronald Reagan. "Win this one for the Gipper" je postao jedan od glavnih političkih slogana Ronalda Reagana.

$A$ winner never quits, and a quitter never wins - Pobjednik nikad ne odustaje a onaj ko odustaje nikada ne pobijedi $A$ quitter never wins, and a winner never quits je takođe varijanta ove izreke.

You can't beat a man at his own game (Ne možeš ga pobijediti u njegovoj igri) - sa značenjem - ne možeš prevazići ljude u njihovom sopstvenom okruženju ili ako su više kvalifikovani. Izreka datira još iz 1756. godine iz Papers of Henry Laurens. Može se čuti u različitim oblicima: Anyone can be fooled at the other man's game; You can't beat the rich at their own game; You can beat the IRS at their own game, itd. (Titelman, 2000).

"No, no, I'll come back, you'll see... I'll beat the bastards at their own game!" he [Konig] added, with a ferocity that startled Queenie. - Michael Korda (1985), Queenie.

"You said you were going to beat Jadwin at his own game. How?" - Philip Friedman (1992), Inadmissible Evidence.

You have to learn to walk before you can run (Moraš da naucičs da hodaš, prije nego što počneš da trčišs) - sa značenjem da se prvo moraju savladati osnove prije nego što se pređe na komplikovanije aktivnosti. Fraza potiče još iz Douce (c.1350), a 1670. godine je uvrštena u knjigu engleskih poslovica Johna Raya. Prvi put je upotrijebljena u Americi u pismu Georgea Washingtona, 1794. godine. Javlja se u raznim oblicima: You must learn to walk. before you can run; You got to learn to walk. before you can run; One mustn't be expected to fly before he is able to walk, itd.

1794 - We must walk as other countries have done before we can run. - George Washington, Writings of George Washington (Titelman, 2000).
1985 - "Do you want me to take my clothes off in any special way?"

"Just take them off the way you normally do," Goldner said, puffing his cigar. "Nothing fancy. We must learn to walk before we can run." - Michael Korda (1985), Queenie.

\section{REZULTATI}

Upoređivanje frazeologizama koji postoje u američkom engleskom i srpskom jeziku pokazuje da je gotovo polovina njih međusobno prevodiva. Naravno, uvijek će postojati i oni koji su stvoreni na lokalnom nivou, kao što je recimo as "kruži kao kiša oko Kragujevca" ili "no joy in Mudville" za koje će prevodioci morati da se oslone na sopstvenu kreativnost. Kada se određen metaforički izraz identifikuje, naredni problem sastoji se od njegovog dekodiranja. Svi autori se slažu da rječnici nisu uvijek pouzdane alatke za rješavanje te vrste problema. Oni prije svega ne sadrže sve frazeologizme, dijelom zato što se svakoga dana stvaraju novi, a dijelom zato što značajno povećavaju fizički volumen rječnika te je stoga često nepraktično da se sve uključi. Postoje frazeologizmi za koje se sa velikom dozom sigurnosti može reći da su univerzalni. Neki od njih su preuzeti iz drugih jezika u obliku koji je upadljivo stran, ali su ipak postali popularni. Takvi su, recimo, „svi putevi vode u Rim", "carpe diem/seize the day", "veni, vidi, vici", "Pirova pobjeda" itd.. Da su iskustva različitih ljudi različita, značenja njihovih simbola bi takođe bila različita, ali nisu (Sanders Peirce, 1935). Stoga se da zaključiti da postoje relativno identični i nevarijabilni elementi u iskustvima svakog člana grupe ljudi.

Ovaj rad je dio šireg istraživanja koje je u razmatranje uzelo metaforičke izraze iz mnogih izvornih domena. Ono što proizilazi iz šire i sveobuhvatnije analize je da su američki frazeologizmi veoma prisutni u svakodnevnom govoru i da pokrivaju razne teme i odnose se na različite sfere života. Imaju veoma pragmatičnu funkciju i korisni su kao instrumenti za izražavanje u raznim situacijama. Mogu da prenose naredbe, osjećanja nezadovoljstva ili sreće. Sa druge strane, srpskim frazeologizmima nedostaje ta vrsta pragmatičnosti koja je sveprisutna u američkom engleskom. Ono što oni imaju da nadomijeste taj nedostatak je njihova evidentna poetičnost. Rima je mnogo prisutnija u srpskoj frazeologiji. Štaviše, 2,5 više srpskih frazeologizama se rimuje od frazeologizama u engleskom jeziku, iako je engleska morfologija pogodnija za rimovanje. Ovo se može objasniti vijekovima usmene tradicije u srpskom jeziku koja preferira rimu i bolje je čuva. 


\section{DISKUSIJA}

Teško je nuditi bilo kakve hipoteze o postojanju objektivnog iskustvenog značenja bez da se ima jasna, provjerena i aksiomatska polazna osnova. „Uzimajući u obzir da je toliko mnogo koncepata koji su bitni za nas ili apstraktno ili nije jasno navedeno u našem iskustvu (emocije, ideje, vrijeme, itd.) moramo da ih pojmimo uz pomoć drugih koncepata koje razumijemo na jasniji način (prostorna orijentacija, predmeti itd.)" (Lakoff i Johnsen, 2003, str. 116). Odnosi između misli, reakcija i metafora su već dugo predmet produktivnih lingvističkih istraživanja (Whorf, 1975).

Mnoge, ako ne i sve, od navedenih izreka i poslovica, iako se upotrebljavaju u Americi su ustvari britanskog porijekla. Chaucer, Shakespeare, i mnogi drugi britanski pisci stvarali su, ili su u mnogome doprinijeli stvaranju, očuvanju i popularizaciji određenih engleskih frazeologizama koje koriste Amerikanci. Frazeologizmi više ne dolaze samo sa britanskih obala. Mnogi od njih se stvaraju u Americi, a potom putuju do Britanije gdje obogaćuju britanski engleski. Čini se da te dvije nacije dijele slične poglede na svijet - "Ono što se može prikazati u rečenicama uključuje aspekte fizičkog svijeta (njegove procese, objekte, odnose, prostorne i vremenske parametre), aspekte 'mentalnog svijeta' misli, osjećanja, osjećaja i tako dalje, kao i aspekte društvenog svijeta" (Fairclough, 2003, str. 134). A ipak, sve te riječi su vezane i za iskustvo, mada putem malo udaljenije i posrednije veze. Ulogu posrednika igra simbol, ili čitav niz simbola koje možemo posložiti u serije u skladu sa nivoom njihove apstraktnosti. To je u skladu sa generalnom semantikom Koržobskog (1948) koja implicira da apstraktnosti uvijek teže ka tome da budu potkrijepljene primjerima. Prema Mckee-u (2003), sama činjenica da ljudi kažu, kada ih upitate, da je to ono što oni misle o određenom tekstu ne znači da je to ono što oni o tome inače misle u svakodnevnom životu.

Oni postoje nezavisno od svijesti bilo kojeg zasebnog pojedinca, mada nisu nezavisni od opštih i zajedničkih subjekata, u ovom slučaju: od svijesti zajednice. U takvoj situaciji, više nije bitno da li koncept uključuje manje ili više elemenata slika ili apstrakcija, ili, drugim riječima rečeno, da li je bliže osjećaju ili misli. Ono što jeste bitno je da li potiče iz određenog iskustva vezanog za sport ili nekog drugog iskustva ili osjećaja (Ogden i Richards, 1923, str. 124), ili je možda putem procesa odvajanja, separacije i izolacije određenih elemenata i razumijevanja ostalih, mada bi se moglo s razlogom tvrditi da svaka konceptualizacija sporta, manifestovana u metaforama sadrži, ili bar indirektno podrazumijeva određene elemente iskustva odvojenog od ostatka sveukupnog iskustva u kojem se inače javlja, generalizovano, ekstrapolirano ili transformirano usljed djelovanja misaonog aparata.

Ovo opet potkrijepljuje misao o dualizmu empirijskog i stvarnog učestvovanja u sportu i kontemplativnog procesa koji ga koristi kao motivaciju. U svom kapitalnom djelu, Ernest Cassirer (1923) je proširio koncept značenja na brojne simboličke forme koje uključuju ljudsko nadmetanje. Lakoff i Johnsen (2003, str. 159) kažu da ljudi ne vjeruju da uopšte postoji objektivna (apsolutna i neuslovljena) istina ili individualno iskustvo vezano za sport, mada je suprotno stanovište na zapadu već dugo prisutno.

\section{ZAKLJUČAK}

Ljudi se međusobno razumiju - ukoliko je aparatura koja analizira naše osjećaje ista. Tu više nije u pitanju kvalitet osjećaja. Pokušaji da se uvede koherentan sistem klasifikacije elemenata uključen u smislene osjećaje nisu novi (Morris, 1946, str. 22). Sportske metafore su raskršća kolektivne svijesti i mudrosti do koje se došlo putem sažetog i metaforičkog iskaza. Zadatak ustanovljavanja porijekla idioma nije nimalo lak. No, ukoliko se ipak upustimo u takav poduhvat ubrzo ćemo shvatiti da njihovu genezu motivišu različiti aspekti ljudskog bivstvovanja, pri čemu sport igra jednu od bitnijih uloga. Oni nisu u jednakoj mjeri prisutni u svim jezicima, ali čini se da su oni koji su vezani za sport veoma produktivni u engleskom jeziku.

\section{LITERATURA}

Buncker, R. (Writer), \& Bacon, L (Dircetor). (1940). Knute Rockne, All American. [Motion picture]. United States: Warner Bros.

Cassirer, E. (1955). The Philosophy of Symbolic Forms. Volume One: Language. New Haven: Yale University Press.

Collins, J. (1986). Hollywood Husbands. New York: Pocket Books.

Dingwaney, A. (1995). Introduction: Translating Third World Cultures, Anuradha Dingwaney and Carol Maier, eds. Between Languages and Cultures, Translation and Cross Cultural Texts. Pittsburgh and London: University of Pittsburgh Press.

Dunne, F. P. (1901). Mr. Dooley's Opinions. New York: R. H. Russell Publisher. 
Fairclough, N. (2003). Analysing Discourse - Textual analysis for social research. London and New York: Routledge.

Fast, H. (1979). The Establishment. Boston: Houghton Mifflin. PMCid: 1818983

Friedman, P. (1992). Inadmissible Evidence. New York: Ivy.

Fulghum, R. (1986). All I Really Need to Know I Leaned in Kindergarten. New York: Villard. PMid: 3775473

Hoffman, A., \& Manning, D. (1952). Takes Two to Tango. [Performed by Pearl Bailey]. [Grammofono record]. Kansas City: Coral Record.

King, S. (1978). The Stand. New York: Signet.

Korda, M. (1985). Queenie. New York: Warner.

Korda, M. (1989). The Fortune. New York: Warner.

Korzybski, A. (1948). Science and Sanity: An Introduction to Non-Aristotelian Systems and General Semantics. Connecticut: Library Publishing Company.

Lakoff, G., \& Johnsen, M. (2003). Metaphors We Live By. London: The University of Chicago press. http:/ /dx.doi.org/10.7208/ chicago/9780226470993.001.0001
Ludlum, R. (1988). The Icarus Agenda. New York: Bantam. PMCid:336791

MacDougall, R. (Producer), \& Rosenberg, S. (Director). 1966. Fame is the Name of the Game. [American TV move]. United states: NBC.

Mckee, A. (2003). Textual Analysis - a beginner's guide. Los Angeles, London, New Delhi, Singapore, Washington DC: Sage.

Morris, C. (1946). Signs, Language and Behaviour. New York: Prentice Hall.

Ogden, C. K., \& Richards, I. A. (1989). Collected Papers. London: Mariner Books.

O'Neill, E. (1959). Strange Interlude. New York: Vintage.

Sanders Peirce, C. (1935). Collected Papers. Cambridge: Cambridge University Press.

Stevenson, R. L., \& Osborne, L. (1892). The Wrecker. London: Cassell \& Company.

Thayer, E. L. (1888, June 3). Casey at the Bat. The San Francisco Examiner, n.p.

Titelman, G. (2000). America's Most Popular Proverbs and Sayings. New York: Random House.

Whorf, L. B. (1975). The Relation of Habitual Thought and Behaviour to Language. Cambridge: Cambridge University Press

Primljeno: 18. mart 2013. godine Izmjene primljene: 5 . jun 2013. godine

Odobreno: 28. jun 2013. godine

Korespondencija:

Dr Dalibor Kesić

Filološki fakultet

Petra Bojivića 1A

78000 Banja Luka

Bosna i Hercegovina

Telefon: 0038765666180

E-mail: bore@blic.net 